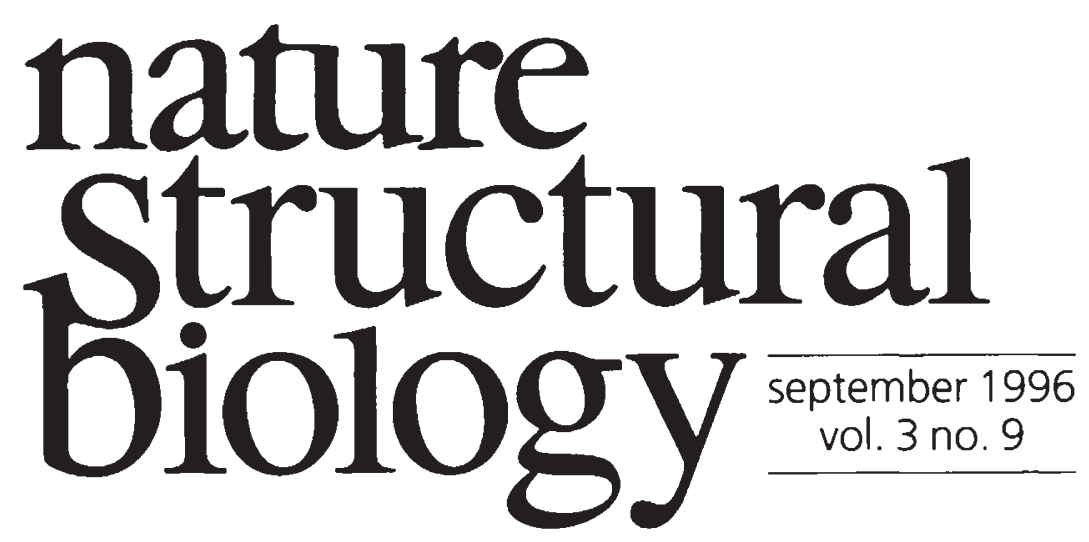

\title{
Bugs from another planet?
}

The suggestion that there is evidence for past life on Mars in the Martian meteorite ALH84001 (ref. 1) has, inevitably, been met with equal servings of wonder and scepticism. As US President Bill Clinton was quick to point out, "if this discovery is confirmed, it will surely be one of the most stunning insights into our universe that science has ever uncovered". With these words hardly uttered others reminded us of the astronomer Carl Sagan's view of such matters: "extraordinary claims require extraordinary evidence".

David McKay and colleagues have been clear from the start that they do not have extraordinary, or even compelling evidence for past life on Mars. Rather they have what may be described as a hint of such a possibility. Certainly, closer scrutiny reveals that their conclusions hinge critically on a number of contentious issues and that the matter is far from being resolved ${ }^{2}$.

Proving that life on Mars did or does exist-even less likely, but as yet not excluded-may take many years. Of the three unmanned missions heading for the planet this year, that being organized by the Russians will be the first to analyse the soil directly, as well as the permafrost that is believed to exist under the surface. It is here that further evidence for past life on Mars might be found. Failing this, the National Aeronautical and Space Administration (NASA) has a sample-return mission scheduled for 2005. This is assuming, of course, that the recent Mars discovery does not go the way of a previous announcement of the discovery of extraterrestrial life, made in the 1960s: features of a meteorite that fell in France in 1864 that were widely believed to be microscopic fossils turned out to be a grain of ragweed pollen and a particle of furnace ash.

Proof of (past) life on Mars would have profound implications for the study of the origins of life. That it may have arisen twice in the same solar system would suggest that life is a rather common feature of the Universe (bookmakers in the United Kingdom have already reduced the odds of finding intelligent life elsewhere from 1 in 500 to 1 in 25). And the Martian life-forms

"Extraordinary claims require extraordinary evidence." Carl Sagan would provide a second independent set of clues about the parameters required for the appearance of self-replicating, self-maintaining systems (assuming, again, that life was not transferred from one planet to the other). What kind of clues would depend very much on the nature of the evidence that may have survived on that now hostile planet. If the present claims turn out to be true then we already have some insight into the size and metabolic capabilities of the (for want of a better name) Martian nanobacteria, and the polycyclic aromatic hydrocarbons found with them would seem to suggest 
that they may be carbon-based organisms, supporting the idea that carbon provides a most versatile chemical framework for life.

We can, of course, never know the details of the transformation that turned chemistry into biology - even on our own planet. The switch from inanimate to animate can only be inferred from our limited understanding of such things as the conditions on the surface of the early Earth and the chemical capabilities of the 'prebiotic soup', as well as clues provided by modern-day evolutionary relics, such as the ribosome and archaebacteria. If the claims of McKay and colleagues hold water, knowledge of the surface of Mars 3.5-4 billion years ago may provide additional insight into the conditions that foster the appearance of life.

A popular hypothesis for one of the first steps on the road to life on Earth is embodied in the idea of the RNA world-where RNA molecules provided both storage of genetic information (genotype) and enzymic activity (phenotype). Experiments reported in this issue of Nature Structural Biology $y^{3}$ on a DNA enzyme (DNAzyme) and in Nature on a self replicating peptide ${ }^{4}$ (and featured on page 762 of this issue) suggest that the prebiotic soup of the RNA world might have been an altogether richer chemical brew.

$\mathrm{Li}$ and $\mathrm{Sen}^{3}$ isolate a DNAzyme capable of inserting a metal ion into a porphryin ring-an important metabolic reaction-by using in vitro selection with a transition-state analogue as a target. Lee and colleagues ${ }^{4}$ demonstrate that a 32 -residue peptide based on the GCN4 leucine zipper, which forms an $\alpha$-helical coiled coil, can catalyse its own synthesis from 15- and 17-mer fragments of itself. Although these result do not provide particularly profound insight into the beginnings of life, they do add to our knowledge of the chemistry of the molecules that were finally selected for being able to sustain a self-replicating, self-maintaining system. Combined with an inkling of the pre-RNA world (and, one imagines, a not inconsiderable amount of luck), we may yet mimic (if not understand) the events of our own origins. Might life still exist on Mars? The atmospheric and surface conditions could not support life as we know it, nor is there any evidence that they do. It is known that bacteria are capable of surviving down to depths several kilometres on the Earth, where conditions are ferociously hostile-thus the last remaining refuge for the long-sought after Martians is beneath the rocky surface of that planet.

In some ways, it is appropriate that the first (as yet

"Hang on a moment, run that Martian bacterial protein sequence past me again: ThrAlaLysGluMetGluThrGInTyrGInValArgLeuGluAlaAspGluArg....."

unconfirmed) encounter with extraterrestrial life may be with a bacteria-like life-form. The history of life on Earth is after all the history of bacteria, for the first 2.5 billion years at least-modern human intelligence being recorded for a mere 200,000 years. Knowing that life almost certainly exists elsewhere would probably still not satisfy Enrico Fermi, though, whose question "OK, but where is everyone?" still remains unanswered. Nor would Blaise Pascal's fears of "the eternal silence of these infinite spaces" be much assuaged by a universe seething with mere bacteria. Origin-of-lifers and exobiologists, on the other hand, would be delighted.

1. McKay, D.S et al. Science 273, 924-930 (1996).

. Grady, M., Wright, I. \& Pillinger, C. Nature 382, 575-576 (1996).

3. Li, Y. \& Sen, D. Nature Struct. Biol. 3, 743-747 (1996).

4. Lee, D.H. et al. Nature 382, 525-528 (1996). 